\title{
Columbia University drops plans to operate reactor
}

LAST week the University of Columbia in New York withdrew a request for a permit from the City of New York to operate a teaching reactor built on the university's Morningside campus in 1969. The university also agreed to withdraw a federal lawsuit, filed jointly with the Department of Justice, challenging the city's jurisdiction over nuclear reactors and radioactive materials.

This move follows a decision by the Faculty of Engineering at Columbia University to accept a request from the president of the university, Dr William J. McGill, not to put the reactor into operation.

Dr McGill had previously resisted moves by members of the local community to prevent the reactor from operating because of health dangers which, some had claimed, would be posed in the case of an accident. However, according to a statement made at a public hearing two weeks ago, Dr McGill said that he had changed his stance mainly in response to public reaction to the Three Mile Island nuclear accident. The university's faculty of engineering has agreed to "acquiesce" to the president's decision. Individually, however, many faculty members disagree with the action, claiming that only increased familiarity with reactor technology will enable operators of the future to avoid the type of mistakes made at Harrisburg.

Students at the university, on the other hand, who have been campaigning against the reactor for many years, claim that the action does not go far enough. They want the reactor, which was constructed in the $1960 \mathrm{~s}$ but has never been operated due to a succession of legal disputes, to be dismantled, and effort to be transferred to solar energy research.

The teaching reactor is a Triga Mark II reactor, and is licensed to operate up to 250 kilowatts, although university officials say that it would only run at an average of 1 kilowatt. The reactor itself cost about $\$ 500,000$, and was financed by the National Science Foundation, with another $\$ 500,000$ being spent on the surrounding building. Similar reactors are already in operation in about 60 universities in both the US and overseas.

Earlier this year, after a series of legal battles over who should have the right to licence the reactor Dr McGill announced that the reactor would still go into operation but not until all the legal aspects had been resolved.

Following the Three Mile Island accident, however, and subsequent

student demonstrations on the Columbia campus, Dr McGill announced that he was going to ask the faculty of engineering to reconsider its plans to operate the reactor. The opposition to the university reactor, which he had previously envisaged to be a political problem, "was clearly revealed during the last week in March and the first week of April as a human problem of mounting seriousness," Dr McGill told the public hearing in New York.

"The Triga issue suddenly acquired the potential to tear the campus apart in an explosion of fear and apprehen-

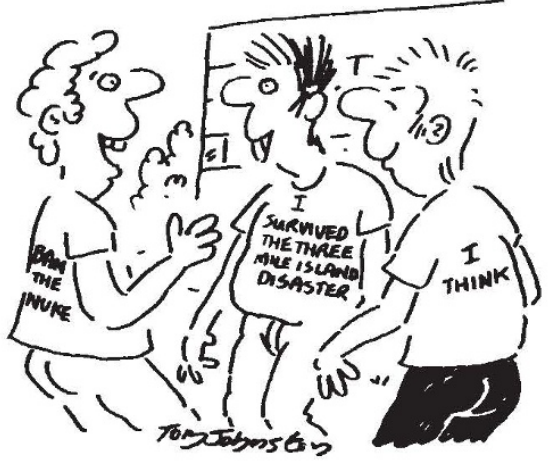

"If there's no reactor to learn from, there'll be nobody to build them!"

\section{Punitive damages for Silkwood contamination}

IN a decision which could have farreaching implications for the US nuclear industry, a jury in Oklahoma City last Friday awarded damages of $\$ 10.5$ million to the three children of Karen Silkwood, an employee of the Kerr-McGee corporation who, it accepted, had been contaminated by plutonium while working in the company's nuclear fuel processing plant.

Miss Silkwood, a laboratory technician in the plant and an activist in the Old Chemical and Atomic Workers Union, was killed in a car accident in 1974 on the way to a meeting with a newspaper reporter at which, she had said, she would produce evidence that Kerr-McGee had carelessly exposed employees to plutonium. After the accident investigators found traces of plutonium in Miss Silkwood's apartment but no papers were found in the car in which she had been travelling.

After a 10-week trial, the jury found the company negligent in the contamination of Miss Silkwood and her apartment, and rejected the charge that she had contaminated herself with plutonium stolen from the plant in sion. The larger interests of safety and well-being affecting everyone at Columbia University required that I act immediately, and I did so."

Faculty members, while agreeing to go along with the president's decision, are criticial both of its implications, and of the way that the decision was taken. "The president's decision was a political one not an educational one; the decision not to operate the reactor is a loss to the country and to the educational community that we cannot afford at the present time," Professor William Havens, director of the university's nuclear science programmes said last week.

The reactor may still be operated in the future. if the general opposition to nuclear power should change, according to Dr Peter J. Likens, dean of the university's school of engineering. "We might seek to reconsider that decision and activate it if the social circumstances mitigate it."

Meanwhile students taking nuclear science and engineering courses at the university may be sent out to the medical research reactor operated by the Brookhaven National Laboratory on Long Island to gain first-hand experience of reactor technology.

David Dickson order to incriminate the company. They awarded Miss Silkwood's estate $\$ 505,000$ in actual damages, and $\$ 10$ million in punitive damages. During the trial, attorney's for the estate argued that working conditions inside the plant were inherently unsafe, and that workers had not been told that plutonium could cause cancer.

Company officials reported that they had informed the Atomic Energy Commission that they had been unable to account for about 40 Ibs of weaponsgrade plutonium, and believed that the material was trapped in pipes in the plant; the prosecution attorneys contended that the company's inability to account for the plutonium was further evidence of its nlegligence. The KerrMcGee plant at which Miss Silkwood worked has since been closed down.

Agents for Miss Silkwood's estate are bringing a further lawsuit against the Oklahoma City Police Force, the FBI and Kerr-McGee concerning the circumstances of her death and a high OCAW official had called for a special government prosecutor to re-open the case. 